\title{
Canadian Association of Gastroenterology Practice Guideline for clinical competence in diagnostic and therapeutic endoscopic retrograde cholangiopancreatography
}

\author{
Alan Cockeram MD FRCPC
}

$\mathrm{T}$ his Practice Guideline is intended to assist individuals, training programs and credentialling bodies in understanding the training for and application of endoscopic retrograde cholangiopancreatography (ERCP), as well as in designating credentialling and maintenance of competence. The Canadian Association of Gastroenterology (CAG) Practice Guideline on training and credentialling provides the necessary background (1). Many of the principles outlined have been previously accepted by CAG (2).

The American Society for Gastrointestinal Endoscopy (ASGE) $(3,4)$ and the American College of Physicians (5) have previously formulated such guidelines.

ERCP is a highly sensitive and technically challenging procedure for diagnosing and treating diseases of the biliary tract and pancreas. ERCP includes partial endoscopic evaluation of the upper gastrointestinal tract, particularly the ampulla of Vater and the second part of the duodenum, followed by cannulation of the ampulla and opacification, selectively if possible, of the biliary tree and/or pancreatic duct. It is recognized that this is an advanced endoscopic technique requiring previous comprehensive training in gastrointestinal disease. The trainee should have a solid basis of routine upper gastrointestinal endoscopy skills before being considered for training in ERCP. The highly invasive nature

\section{SPONSORS AND VALIDATION}

This practice guideline was developed by Alan Cockeram MD FRCPC and was reviewed by:

The Practice Affairs Committee (Chair - $\mathrm{Dr}$ A Cockeram): Dr T Devlin, Dr HM MacSween, Dr J McHattie, Dr D Petrunia and Dr E Semlacher

Dr A Barkun, Dr J Connon, Dr G Haber, Dr R Brent Scott

Canadian Association of Gastroenterology (CAG) Governing Board

CAG Endoscopy Committee (Chair - Dr B Selena)

CAG Program Directors Committee (Chair Dr D Leddin)

of ERCP and its greater risk of procedure-induced complications demand prudence in patient evaluation and greater technical skills. There are no short cuts in the acquisition of required skills although mechanical models and computer modelling may facilitate training (6). Nothing, however, will replace exposure to a large variety of clinical situations.

With the use of ERCP, morbidity rates of $7 \%$ to $10 \%$ and mortality rates as high as $1.2 \%$ have been reported $(7,8)$. 
TABLE 1

Potential indications for endoscopic retrograde cholangiopancreatography

Evaluation of the patient with jaundice thought to be due to obstruction

Evaluation of the patient with symptoms suggestive of disease of the biliary tree or the sphincter of Oddi

Sepsis suspected to be of biliary origin

Abnormal liver function presumed to be of biliary cause

Suspicion of bile duct injury

Evaluation of the patient with suspected pancreatic disease or when further management may be indicated when ultrasound and computed tomographic scan are not diagnostic

Recurrent pancreatitis of unknown etiology or, in some cases, after the first episode of pancreatitis

Evaluation of patients with pancreatic pseudocyst before surgical or endoscopic therapy

Severe persisting or recurrent pain presumed to be of pancreatic or biliary origin when other less invasive investigations have proven nondiagnostic

\section{TABLE 2}

\section{Potential contraindications to endoscopic retrograde cholangiopancreatography}

Intestinal obstruction

Suspected perforated viscus

High risk patients in whom the potential benefit does not justify the risk

Insufficient endoscopic skills

Recognizing these risks, extensive initial training and regular ongoing experience are imperative to remain facile in this procedure and to minimize complications (personal communication, 9,10).

While learning the procedure, the trainee's performance must be directly supervised by an experienced endoscopist who regularly performs the procedure, and can adequately communicate to the trainee the information necessary to acquire these skills. An experienced endoscopist must subsequently evaluate the trainee; this should include written documentation of the experience of the trainee including the date, patient number, patient age, indication for the procedure, successful cannulation of each duct, duration of the procedure, findings and procedure complications (11). A log book should be maintained by each trainee, with the training endoscopist ideally initialling the log at regular intervals.

Recognition of both cognitive and technical aspects of training is expected. The trainee must be involved in the clinical evaluation of patients requiring ERCP in order to understand fully the clinical application of the procedure. In addition, the trainee should be involved in the care of patients following both uncomplicated and complicated ERCP.

Table 1 lists potential indications for ERCP. While no list is totally comprehensive, the majority of procedures should
TABLE 3

Situations in which endoscopic retrograde cholangiopancreatography is generally not indicated

Obscure pain without objective clinical findings or laboratory data to suggest biliary or pancreatic disease

A single episode of acute pancreatitis without suggestion of biliary tract disease or neoplasm

Evaluation of pancreatic carcinoma where other tests are diagnostic and there is no evidence of biliary obstruction

Evaluation of the gallbladder without evidence of bile duct disease

\section{TABLE 4}

Cognitive skills necessary to assess competently the need for and application of endoscopic retrograde cholangiopancreatography

Knowledge of the roentgenographic anatomy of the pancreas,

biliary tree and duodenum, and variations in papillary anatomy

Knowledge of the clinical indications for the procedure

Knowledge of the contraindications to the procedure

Knowledge of alternatives

Ability to distinguish a complete from an incomplete examination

Ability to identify gross pathology accurately

Ability to recognize abnormal anatomical or pathological conditions that preclude successful and safe conclusion of the examination

Ability to identify the need for tissue sampling

Ability to identify and manage high risk patients

Ability to identify and manage complications

Ability to communicate the risks, benefits and results of the procedure to the medical record, others involved in care and the patient so that the patient is able to consent or refuse in an appropriately informed fashion

Ability to develop a plan for further treatment and follow-up based on the results of the procedure

Knowledge of appropriate handling of tissue samples to allow correct processing by pathology

Knowledge of appropriate preprocedure- and procedure-related medications, including the need for prophylactic antibiotics, and the ability to manage any adverse reactions

Ability to provide medical monitoring, and prompt and appropriate medical intervention, and to coordinate efforts with others involved in care of the patient

fulfil one of these criteria. These indications may change as technology changes. Potential contraindications to ERCP are listed in Table 2 but these may not be exhaustive. A number of situations arise in which ERCP is usually not helpful and generally not indicated. These are listed in Table 3. These indications and contraindications are intended to serve as a guideline, recognizing that such lists will never be all inclusive and need to be used with the clinical judgement of the experienced endoscopist and need to be updated with advances in medical care. Table 4 outlines the cognitive skills necessary to assess competently the need for and application of ERCP (5). 
Technical skills required to perform ERCP include a reasonable knowledge of the instrument and its care and disinfection; the ability to introduce, manipulate and withdraw the endoscope and allied instruments; and the ability to complete the procedure in an acceptable period of time with adequate patient comfort. These skills should result in the ability to cannulate the desired duct in at least $90 \%$ of attempts. It is expected that the endoscopist will ensure that appropriate equipment, nursing and technical staff, and other supportive services as necessary will be available.

Purely diagnostic ERCP by individuals unskilled in the application of therapeutic modalities in ERCP is inappropriate in the current clinical climate. Patients requiring investigation for the aforementioned clinical applications frequently will benefit from therapy that can often be applied endoscopically with greater safety and patient comfort than with other approaches. Clearly not all individuals who have undergone training in ERCP have acquired the necessary skills for treatment of all diseases encountered. However, the ability to relieve obstruction successfully when indicated and to remove stones when indicated has now become a required skill. A selection of common indications for therapeutic modalities in ERCP are listed in Table 5.

\section{MINIMUM TRAINING STANDARDS}

Threshold for evaluation: Numbers alone should never be the criterion for evaluation of training. However, the concept of a minimum 'threshold' of procedures that must be completed before the trainee may be evaluated has gained increasing acceptance (12). This concept is now validated for other endoscopic procedures (13-15) and for ERCP $(16,17)$.

The ASGE previously suggested a minimum of 75 diagnostic procedures and 25 additional therapeutic procedures $(18,19)$. However, objective evaluation of trainees suggested that these previously accepted numbers are too low. More recent data presented by Jowell et al (16), requiring a success rate of at least $80 \%$ in each of seven different criteria, confirm that at least 180 ERCP procedures are required to achieve technical competence in all components of ERCP. Many of these trainees had had prior ERCP experience and selected a career stream in therapeutic endoscopy (16). Data confirming that greater proficiency lead to better outcomes are not yet published. It is therefore advised that the performance of 180 ERCPs be the threshold for evaluation.

The ASGE has recently proposed that no minimal number of procedures be used; rather, that competence be defined as the ability to cannulate the desired duct selectively and freely at least $80 \%$ of the time without assistance (20). The learning process may progress at different rates for individuals, but there is evidence that surgical trainees acquire endoscopic skills no faster than medical trainees (13). It should be incumbent on the trainee to demonstrate success in all facets of ERCP in greater than $80 \%$ of attempts. Trainees and program directors should recognize that most trainees will require at least 180 procedures to achieve this level of competence. The mere completion of this minimum

\section{TABLE 5 Indications for endoscopic sphincterotomy and/or stent insertion}

Choledocholithiasis
Sump syndrome
Ampullary stenosis
Sphincter of Oddi dysfunction (types I and II)
Management of patients with bile duct injury
Placement of biliary stent or nasal biliary drain for management of
benign or malignant biliary obstruction
Stent placement for prevention of obstruction where stone
extraction is not possible at that time
Ductal cannulation in selected cases (ie, precut sphincterotomy)
Management of selected pancreatic pseudocysts
Management of selected pancreatic duct strictures, stones and
sphincter of Oddi dysfunction

threshold number does not imply competence. A statement from the training endoscopist, in writing, based on the trainee's log should be required, indicating competence in different facets of endoscopy. "It is the trainer's responsibility, both ethical and legal, to be certain that the physicians they certify are indeed competent in the certified skills" (21).

Maintenance of competence: As noted above, regular performance of ERCP is necessary to maintain acquired skills. Infrequent performance of the procedure may lead to inappropriate application of the procedure, incorrect diagnoses and lower success rates with higher rates of complications. It is suggested that institutions catalogue all procedures as part of quality assurance programs so that review of outcomes may be facilitated if required.

Maintenance of competence requires an ongoing use of acquired skills. Again the number of procedures needed is difficult to apply rigidly; it was suggested in a survey of practicing gastroenterologists that a minimum of 50 procedures per year is required (22).

Granting of privileges should be applied in each institution by a multidisciplinary committee of members knowledgable in endoscopic procedures and their clinical usefulness and application. "Today, hospitals have a duty to exercise due care in granting privileges to physicians, and they expose themselves to liability for granting specialized privileges to physicians/surgeons who are poorly trained, inexperienced with specific procedures, or insufficiently knowledgable about the relevant disease areas" (23). This process should also address the need for individuals with such skills in the institution $(24,25)$. This issue has been addressed in another CAG Practice Guideline (1). Completion of a gastrointestinal or surgical fellowship alone does not imply acquisition of the necessary skills. Short courses in endoscopy offer inadequate hands-on experience and will not result in competence (26).

Proctoring may prove to be a useful technique to ensure that applicants have the necessary skills (25). 


\section{REFERENCES}

1. MacSween HM. Canadian Association of Gastroenterology guidelines for granting privileges to perform gastrointestinal endoscopy. 1997;11:429-32.

2. Bailey RJ, Barkun A, Brow J, et al. Consensus in Endoscopy. Can J Gastroenterol 1996;10:237-42.

3. American Society for Gastrointestinal Endoscopy. Statement on Endoscopic Training. ASGE Publication No 1001. Manchester: American Society for Gastrointestinal Endoscopy, 1986.

4. American Society for Gastrointestinal Endoscopy. Methods of Granting Hospital Privileges to Perform Gastrointestinal Endoscopy. ASGE Publication No 1012. Manchester: American Society for Gastrointestinal Endoscopy, 1992.

5. American College of Physicians. American College of Physicians position paper: Clinical competence in diagnostic endoscopic retrograde cholangiopancreatography. Ann Intern Med 1988;108:142-4.

6. Williams CB, Baillie J, Gillies DF, et al. Teaching gastrointestinal endoscopy by computer simulation: A prototype for colonoscopy and ERCP. Gastrointest Endosc 1990;36:49-54.

7. Cotton PB, Lehman G, Vennes J, et al. Endoscopic sphincterotomy complications and their management: an attempt at consensus. Gastrointest Endosc 1991;37:383-93.

8. Freeman M, Nelson D, Sherman S, et al. Complications of endoscopy biliary sphincterotomy. N Engl J Med 1996;335:909-18.

9. Leung JW, Chung RS. Training in ERCP. Gastrointest Endosc 1992;38:517-8.

10. Brandt L. Training in gastrointestinal endoscopy. Gastrointest Endosc 1992;38:88-9.

11. Bond JH. Evaluation of trainee competence. Gastrointest Endosc Clin North Am 1995;5:337-46.

12. Baillie J, Ravich WJ. On endoscopic training and procedural competence. Ann Intern Med 1993;118:73-4.

13. Cass OW, Freeman ML, Peine CJ, et al. Surgeons and GI Fellows do not differ in the acquisition of endoscopy skills during training. Gastrointest Endosc 1994;40:P39. (Abst)

14. Marshall JB. Technical proficiency of trainees performing colonoscopy: a learning curve. Gastrointest Endosc 1995;42:287-91.

15. Cass OW, Freeman ML, Cohen J, et al, and the Fellowship ACES Study Group. Acquisition of competency in endoscopy skills during training. Gastroenterology 1996;110:A3496.

16. Jowell PS, Baillie J, Branch MS, Affronti J, Browning C, Bute BP. Quantitative assessment of procedural competence. A prospective study of training in endoscopic retrograde cholangiopancreatography. Ann Intern Med 1996;125:983-9.

17. Wigton RS. Measuring procedural skills. Ann Intern Med 1996;125:1003-4.

18. Cass OW, Freeman ML, Peine CJ, Zera RT, Onstad GR. Objective evaluation of endoscopy skills during training. American College of Physicians 1993. Ann Intern Med 1993;118:40-4.

19. Fleischer D. Advanced training in endoscopy. Gastrointest Endosc Clin North Am 1995;5:311-21.

20. American Society for Gastrointestinal Endoscopy. Guideline For Advanced Endoscopic Training. ASGE Publication No 1026. Manchester: American Society for Gastrointestinal Endoscopy, 1994.

21. Friedman LS. How long does it take to learn endoscopy? Gastrointest Endosc 1995;42:371-3.

22. Wigton RS, Blank LL, Monsour H, Nicholas JA. Procedural skills of practicing gastroenterologists. Ann Intern Med 1990;113:540-6.

23. Sundermeyer MS, Murphy PA. Prevention of hospital liability for granting privileges to unqualified physicians. Gastrointest Endosc Clin North Am 1995;5:433-45.

24. Sivak MV. Privileges to perform endoscopy. Am Soc Gastrointest Endosc 1990;36:73-4.

25. American Society for Gastrointestinal Endoscopy. Proctoring and hospital endoscopy privileges. Gastrointest Endosc 1991;37:666-7.

26. Sivak MV. Advanced training in gastrointestinal endoscopy. Gastrointest Endosc 1992;38:90-1. 


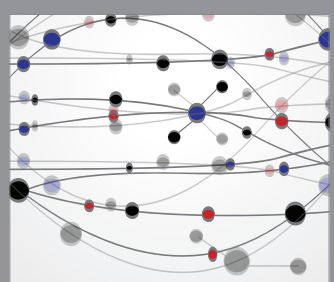

The Scientific World Journal
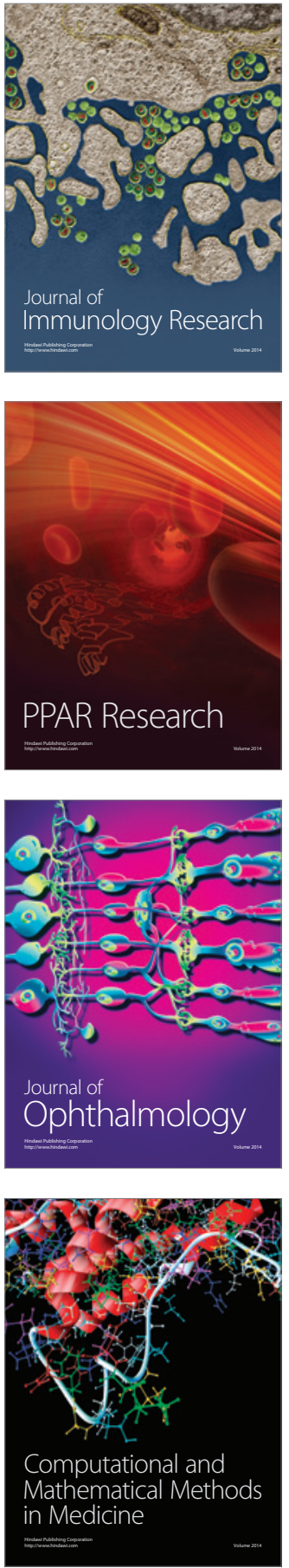

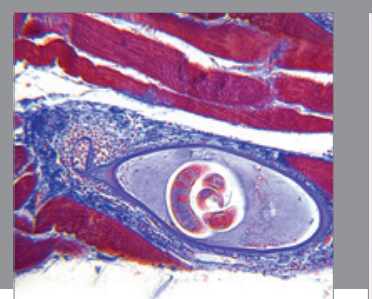

Gastroenterology Research and Practice

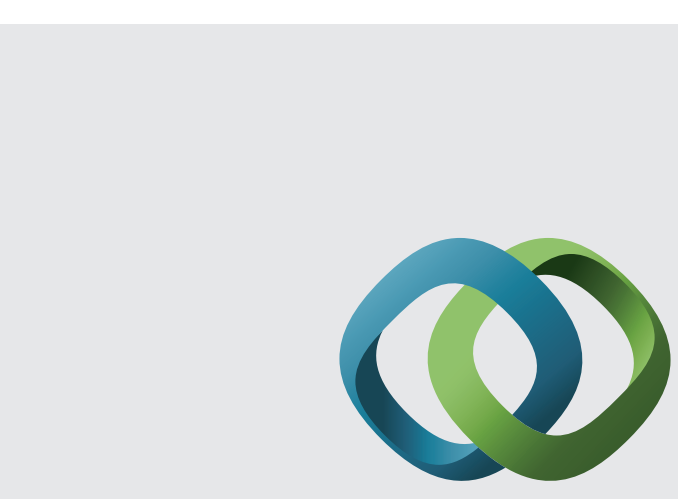

\section{Hindawi}

Submit your manuscripts at

http://www.hindawi.com
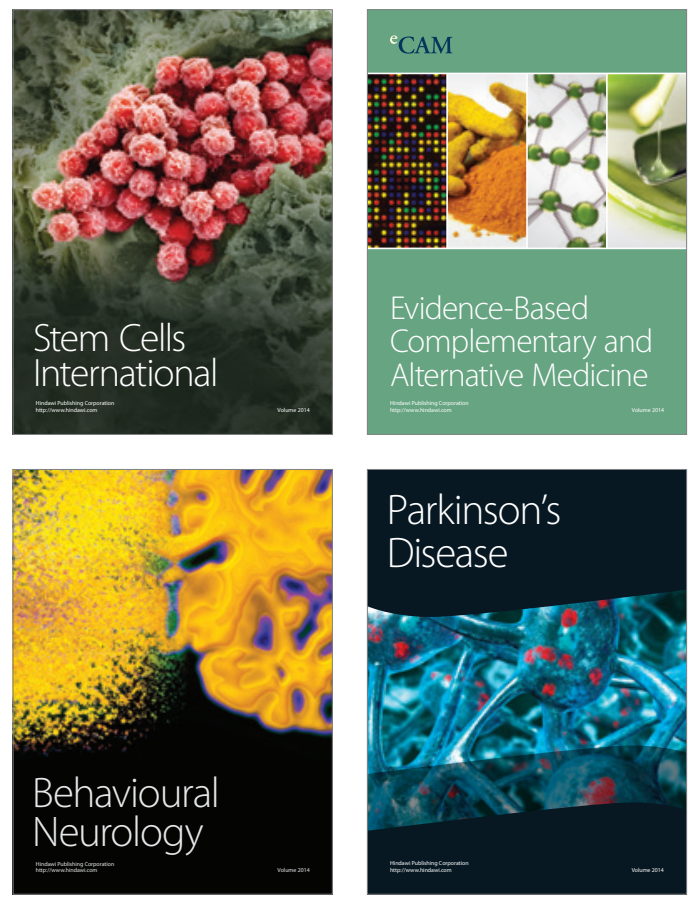
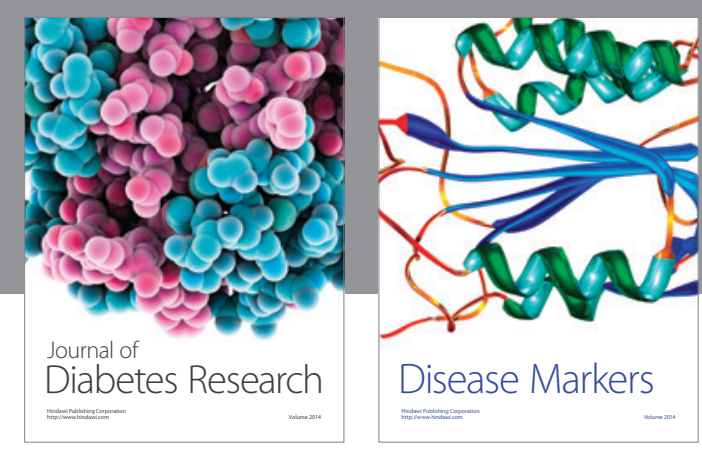

Disease Markers
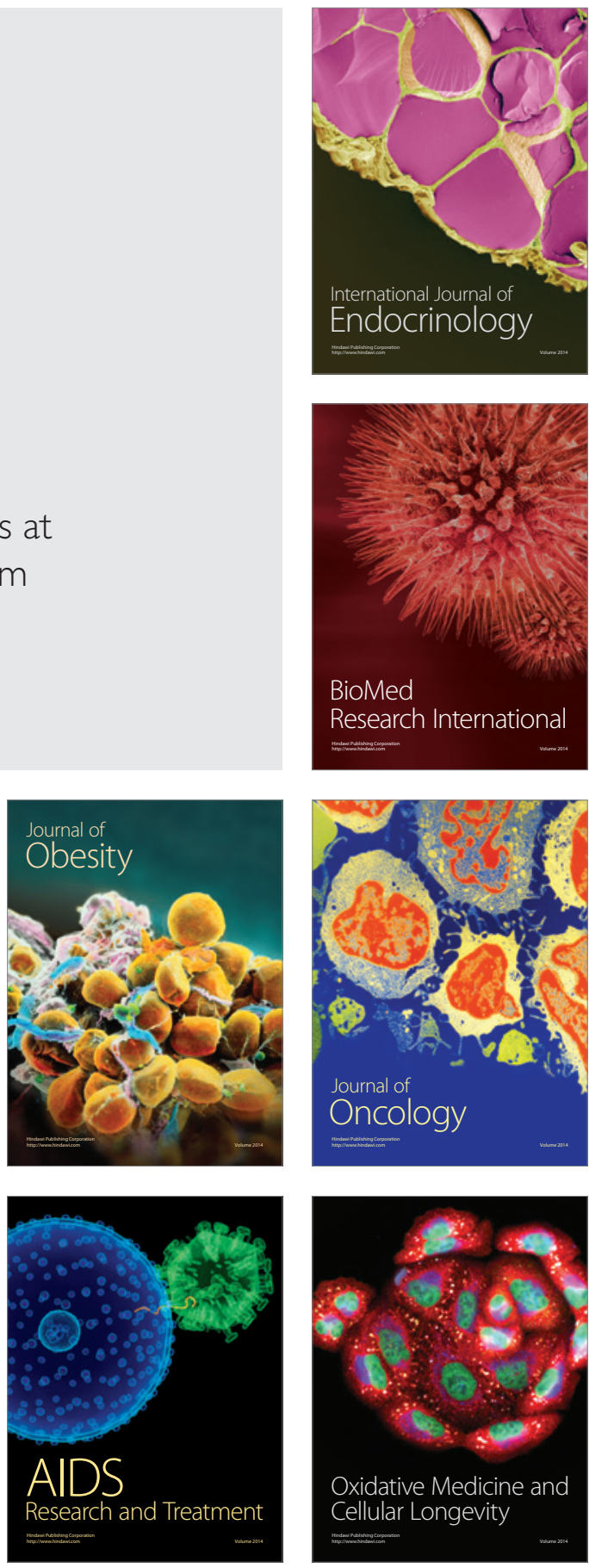